\title{
Continuous Niobium Phosphate Catalysed Skraup Reaction for Quinoline Synthesis from Solketal
}

Jing Jin, ${ }^{a}$ Sandro Guidi, ${ }^{\mathrm{a}, \mathrm{b}}$ Zahra Abada, ${ }^{\mathrm{a}}$ Zacharias Amara, ${ }^{\mathrm{a}, \mathrm{c}}$ Maurizio Selva, ${ }^{\mathrm{b}}$ Michael W. George ${ }^{\mathrm{a}, \mathrm{d}}$ and Martyn Poliakoffa*

aschool of Chemistry, University of Nottingham, University Park, NG7 2RD, Nottingham, United Kingdom.

bDepartment of Molecular Sciences and Nanosystems, Università Ca' Foscari Venezia Via Torino 155, 30172 Venezia-Mestre, Italy.

'Laboratoire Chimie Moléculaire Génie des procédés chimiques et énergétiques, CNAM, 2 rue Conté, 75003, Paris, France.

dDepartment of Chemical and Environmental Engineering, University of Nottingham Ningbo China, 199 Taikang East Road, Ningbo 315100, China.

Key Words: Niobium phosphate, acid-catalysed, quinoline, Skraup reaction, Indole, Continuous

\begin{abstract}
Solketal is derived from the reaction of acetone with glycerol, a by-product product of the biodiesel industry. We report here the continuous reaction of solketal with anilines over a solid acid niobium phosphate (NbP), for the continuous generation of quinolines in the the well-established Skraup reaction. This study shows that $\mathrm{NbP}$ can catalyse all stages of this multistep reaction at $250{ }^{\circ} \mathrm{C}$ and 10 MPa pressure, with a selectivity for quinoline of up to $60 \%$. We found that the catalyst eventually deactivates, most probably via a combination of coking and reduction processes but neverthless we show the promise of this approach. We demonstarted here the application of our approach to synthesize both mono- and bis-quinolines from the commodity chemical, 4,4'-methylenedianiline.
\end{abstract}

Key words: Niobium phosphate, Skraup reaction, acid-catalysed, quinoline, indole, continuous flow

\section{Introduction}

Significant advances in the production of fuels, fine chemicals, and high valuable products from renewable feedstocks have been achieved over the past decade. ${ }^{1}$ Biomass has emerged as one of the most important sustainable sources for renewable organic carbon in line with the Principles of Green Chemistry. ${ }^{2,3}$ In this context, renewable energy sources derived from biomass such as biodiesels, offer opportunities to access glycerol, an inexpensive by-product representing $10 \% \mathrm{wt}$ of the overall 
production. ${ }^{4,5}$ The current increased production of biodiesel generates an ever greater abundance of glycerol to the point where supply exceed demand. ${ }^{6}$

The possibility of using glycerol as a precursor to other chemicals has therefore attracted increasing attention in recent years. ${ }^{7,8}$ The chemistry of glycerol is widely developed as summarised in a number of major reviews. ${ }^{910,11}$ Among the varied transformations, the Skraup reaction stands out as one of the few that enables the direct transformation of glycerol into heteroaromatic compounds such as quinolines, which are an important class of hetero-aromatic compounds with large scale industrial applications. $^{12}$

The Skraup reaction is relatively old; it was first described ${ }^{13}$ in 1880 but remains somewhat underexploited. It relies on the dehydration of glycerol to form acrolein, a highly reactive intermediate, which subsequently condenses with aniline. Typically, it requires stoichiometric quantities of harsh and/or toxic soluble reagents such as concentrated sulfuric acid, nitrobenzene and a range of metal salts and strong oxidants (Scheme 1, top). ${ }^{14}$

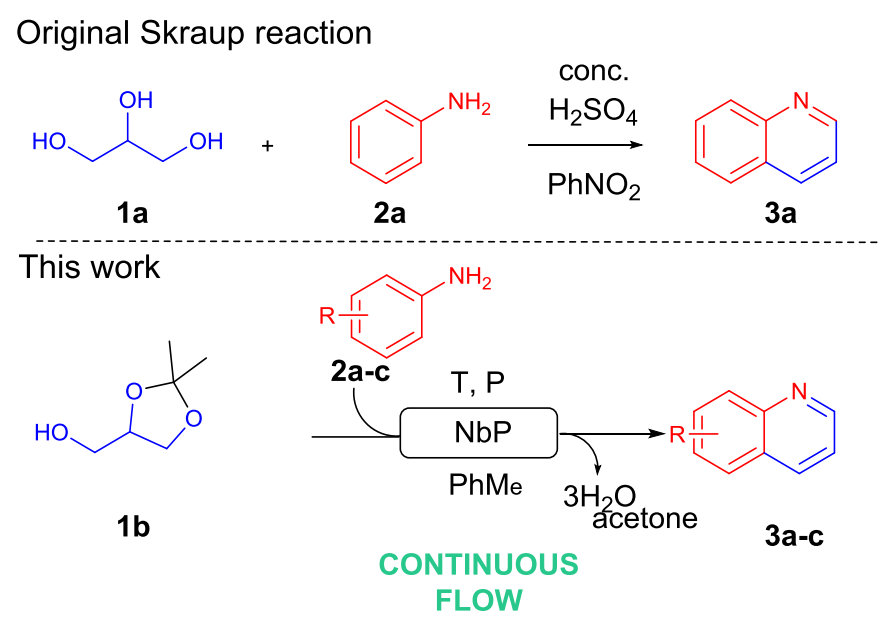

Scheme 1. Original Skraup reaction ${ }^{13}$ and the continuous flow Skraup reaction of solketal $\mathbf{1 b}$ and anilines $\mathbf{2}$ over niobium phosphate (NbP) described in this paper.

More recently, a range of catalytic routes have been developed; however these procedures generate considerable amounts of waste and have to be performed under relatively harsh conditions, tedious and lengthy workup. ${ }^{15,16,17,18}$ The large quantities of waste, harsh reagents and conditions mean that this reaction is often overlooked as a viable route despite one of the main reagents being glycerol. Even though, modified conditions have been developed, ${ }^{19,20}$ the use of an oxidant and corrosive acid or expensive ionic liquids ${ }^{21}$ remain necessary. 
From a green point of view, routes such as the Skraup reaction, which involve homogenous acids, are associated with problems of toxicity, corrosion, use of stoichiometric quantities, separation and recovery. Heterogeneous catalysts potentially offer a greener alternative as they can be easily separated at the end of a reaction and can often be recycled, reducing the environmental cost of a chemical process. Furthermore, solid acid catalysts can combine aspects of both Brønsted and Lewis acidity offering a versatile alternative to homogeneous acids, particularly in terms of acid strength, number of active sites and support morphology (e.g. surface area and porosity). Several heterogeneous catalytic systems have already shown to be active in the dehydration of glycerol to acrolein; these include zeolites,,$^{22,23}$ heteropolyacids,,$^{24,25,26,27}$ and metal oxides..$^{28,29}$

In this report we use niobium phosphate (NbP) as a heterogeneous acid catalyst that exhibits strong surface acidity and has been successfully used in the past to catalyse several reactions, ${ }^{30}$ including the dehydration of several bio-derived compounds such as $x$ lose, ${ }^{31}$ fructose, $^{32}$ cellulose $^{33}$ and glycerol. ${ }^{28,34} \mathrm{NbP}$ has acidic catalytic properties similar to niobium oxide. ${ }^{35,36,40}$ However, its acidic properties are more stable than those of the oxide at higher temperatures $\mathrm{s}^{37,38}$ and frequently NbP limits side reactions as a result of additional Brønsted sites. ${ }^{39}$ Moreover, NbP has been demonstrated to be an effective catalyst for reactions in which water molecules are present or generated..$^{40}$

Inorganic solid acid catalysts are generally highly insoluble in organic solvents which make them suitable for applications in continuous flow processes. Tubular reactors can be easily filled with the solid acid to make a fixed-bed system that can be coupled to a flow setup allowing the continuous catalytic processing of reagents. Such reactors provide enhanced heat and mass transfer while offering opportunities for optimization and therefore simpler scale-up and greater safety. ${ }^{41}$ Furthermore, enhanced reactions rates are often observed because of high local concentrations. ${ }^{42}$

Given the previous reports ${ }^{43,44}$ of the dehydration of glycerol and other biomass derived compounds $s^{45,46,47}$ using Niobium based catalysts, we have investigated how these catalysts might be used in a continuous flow system to develop a Skraup reaction that provides a greener, cleaner and continuous synthesis of quinoline derived products (Scheme 1, bottom).

\section{Results and Discussion}

The small scale of our equipment means that pure glycerol is too viscous to be pumped through the narrow-bore of the pipework. Therefore, the glycerol needs to be diluted with a solvent to reduce its viscosity. Unfortunately the choice of solvent is limited. Thus, starting point was to react glycerol 1a and aniline $\mathbf{2 a}$ with water as the solvent. In addition to its obvious lack of toxicity, water allows a high concentration of glycerol to be used and it is also compatible with the niobium catalysts. ${ }^{48}$ However, 
whilst glycerol is soluble in water, aniline on the other hand has only limited miscibility to a maximum of ca. $0.4 \mathrm{M} .{ }^{49}$ The highest yield of quinoline 3a that could be achieved was only $10 \%$ despite our testing of a range of parameters (temperature, pressure, flow rate, reagent stoichiometry). Even though the yield was low, it was an encouraging proof of concept. The remaining reaction products were often a complicated mixture. We have reported in previous work that aniline reacts with polar solvents, such as small alcohols, in presence of $\mathrm{NbP}$ resulting in alkylation reactions. ${ }^{30}$ Since glycerol is only soluble in water or very polar protic solvents, we decided to switch to an alternative reagent, solketal $\mathbf{1 b}$, which is the isopropylidene acetal-protected form of glycerol. It is produced by the condensation of acetone with glycerol. ${ }^{50}$ As two of its hydroxyl groups are protected, solketal is less prone to hydrogen bonding than glycerol and is soluble in a wider range of solvents.

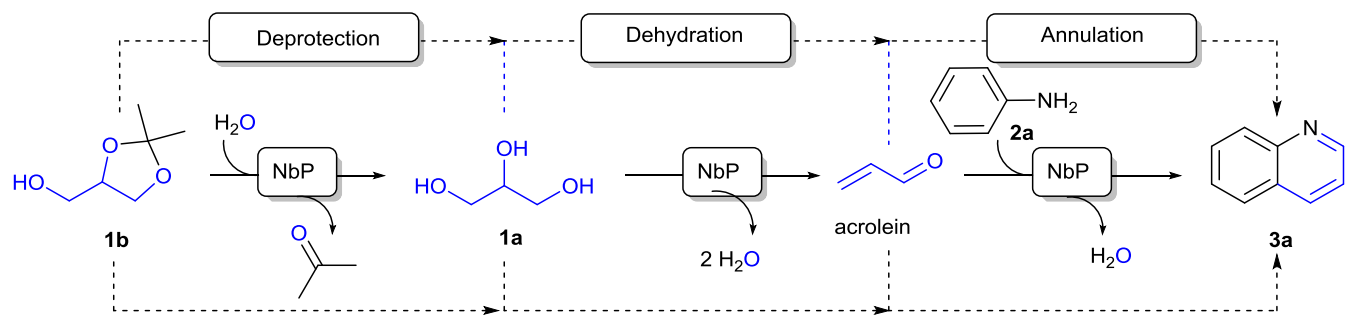

Scheme 2. The Multiple roles of niobium phosphate in the synthesis of quinoline $\mathbf{3 a}$ from solketal $\mathbf{1} \mathbf{b}$. The three-step transformation is envisaged as a single continuous process.

We envisaged that reaction with the acidic $\mathrm{NbP}$ would deprotect $\mathbf{1} \mathbf{b}$ to regenerate glycerol allowing its subsequent dehydration to acrolein. This should allow to the Skraup reaction to proceed in a slower more controlled manner (Scheme 2). It was anticipated that this approach might avoid the large quantities of by-products observed in our preliminary experiments. With a larger choice of solvents available, the problem of poor aniline solubility could also be overcome. To minimize potential alkylation reactions protic solvents were avoided and a more inert solvent was chosen; we ultimately settled on toluene as the solvent for the reaction.

Our strategy has been to investigate the reaction of solketal with aniline to identify the best conditions in terms of conversion and selectivity as a function of pressure, temperature, reactor volume and ratio of aniline to solketal. Then we applied the reaction to two further anilines 3-methoxyaniline (MA) and 4,4'-methylenedianiline (MDA). Of course, the use of solketal represents unnecessary derivatization (in contradiction to the Green Chemistry Principle No. 8) but on a larger scale the viscosity of neat glycerol would be less of a problem and its the replacement by solketal would not be required. However, solketal does allow these continuous reactions to explore on a laboratory scale. 
Solketal $\mathbf{1 b}$ and aniline $\mathbf{2} \mathbf{a}$ were delivered via independent HPLC pumps; the reactor was filled with $\mathrm{NbP}$ and different parameters were explored to optimise the reaction. The initial temperature was $250{ }^{\circ} \mathrm{C}$ as this had previously been identified as the best for the dehydration step of glycerol. ${ }^{51}$ The reaction was carried out at low pressure with a ratio aniline to solketal (2a:1b) of 1:3 to allow for possible loss of acrolein by polymerisation. The flow rate for solutions of both $\mathbf{2} \mathbf{a}$ and $\mathbf{1} \mathbf{b}$ were set at $0.1 \mathrm{~mL} / \mathrm{min}$.

The results are shown in Figure 1 and it is clear that: (i) the conversion of aniline, as measured by GC, decreased very rapidly with time, at $0.1 \mathrm{MPa}$ pressure; (ii) as the pressure was increased the rate of drop off was slower; (iii) increasing the pressure above $5 \mathrm{MPa}$ had no further effect; (iv) the selectivity for quinoline 3 was never above $60 \%$ and reduced over time; $(v)$ the reduction in selectivity appears to be greater at lower pressure.
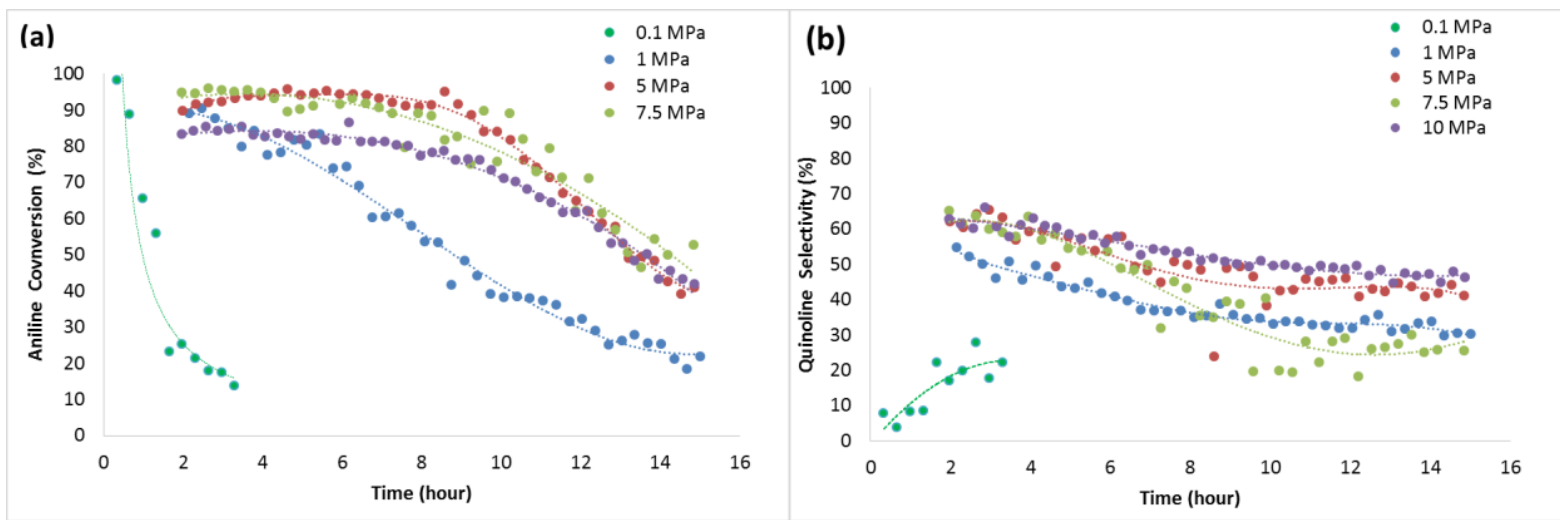

Figure 1. Effect of the system pressure on the (a) aniline conversion and (b) quinoline selectivity over $\mathrm{NbP}$. The different experiments were performed under the following conditions: $250{ }^{\circ} \mathrm{C}, 0.2 \mathrm{~mL} / \mathrm{min}$ of total flowrate for $1: 3$ ratio of $\mathbf{2 a : 1 b}$ in toluene.

Table 1. Physical properties of the reagents and products involved in the reaction.

\begin{tabular}{|c|c|c|c|}
\hline Compounds & Boiling point $\left({ }^{\circ} \mathrm{C}\right)$ & $\mathrm{T}_{\mathrm{c}}\left({ }^{\circ} \mathrm{C}\right)$ & $\mathrm{P}_{\mathrm{c}}(\mathrm{MPa})$ \\
\hline Toluene & 110.6 & 318.6 & 4.11 \\
\hline Glycerol & 290.0 & 492.2 & 4.31 \\
\hline Solketal & $188.0-190.0$ & - & - \\
\hline Acrolein & 53.0 & 254.0 & 5.07 \\
\hline Aniline & 184.2 & 425.6 & 5.31 \\
\hline 4-Methoxyaniline ${ }^{\ddagger}$ & 246.0 & - & - \\
\hline
\end{tabular}




\begin{tabular}{llll}
\hline 4,4'-methylenedianiline & 398.0 & - & - \\
Quinoline 3a & 237.0 & - & - \\
3-methylindole 3b & 265.5 & - & - \\
\hline
\end{tabular}

${ }^{\ddagger}$ melting point $57^{\circ} \mathrm{C} . " \|$ melting point $89^{\circ} \mathrm{C}$.

The effect of pressure in fact can be rationalised, at least qualitatively, by looking at the physical data in in toluene.

Table 1. Apart from glycerol, all the reaction components will be in the vapour phase at $250{ }^{\circ} \mathrm{C}$ and $0.1 \mathrm{MPa}$ pressure. Increasing the pressure will create a two phase system and most probably the entire reactor is filled with liquid at pressure $>5 \mathrm{MPa} .{ }^{52,53}$ This switch from vapour to liquid phase will give higher volumetric concentrations of reactants and longer residence times for a given flow rate of reactants into the system (Table 2 ).

Table 2. Influence of the pressure on the conversion of aniline, quinoline $3 a$ selectivity and productivity over NbP.

\begin{tabular}{lcccc}
\hline Pressure & $\mathbf{1 ~ M P a}$ & $\mathbf{5 ~ M P a}$ & $\mathbf{7 . 5} \mathbf{~ M P a}$ & $10 \mathrm{MPa}$ \\
\hline Aniline conversion $^{\mathrm{a}}$ & $71 \%$ & $90 \%$ & $90 \%$ & $80 \%$ \\
Quinoline selectivity $^{\mathrm{a}}$ & $44 \%$ & $53 \%$ & $49 \%$ & $57 \%$ \\
Quinoline productivity & $0.067 \mathrm{~g} / \mathrm{h}$ & $0.1 \mathrm{~g} / \mathrm{h}$ & $0.093 \mathrm{~g} / \mathrm{h}$ & $0.1 \mathrm{~g} / \mathrm{h}$
\end{tabular}

${ }^{a}$ The conversion, selectivity and productivity were averaged between $2^{\text {nd }}$ and $10^{\text {th }}$ hour and calculated based on GC analysis. Reaction conditions were $\mathbf{2 a : 1 b}$ ratio of $1: 3$ and $0.2 \mathrm{ml} / \mathrm{min}$ total flowrate, 250 ${ }^{\circ} \mathrm{C}$ at $10 \mathrm{MPa}$.

The major by-product was isolated by column chromatography and was identified via NMR and mass spectrometry as 3-methylindole $\mathbf{3 b}$. Its formation can be understood as arising from the reaction of hydroxyacetone with aniline (Scheme 3). ${ }^{54}$ Hydroxyacetone has previously been reported ${ }^{55}$ as being formed from acrolein in presence of Lewis acid sites. ${ }^{56,57}$ Over Lewis acid sites, coordination of the glycerol intermediate takes place, leading to the removal of water from a primary $\mathrm{OH}$ group of glycerol as reported previously. ${ }^{58}$ This results in an unstable enol intermediate, which undergoes a rapid tautomerisation to hydroxyacetone. Similar mechanisms have been observed over $\mathrm{La}_{2} \mathrm{CuO}_{4}$ as a catalyst explaining the occurrence of hydroxyacetone $\mathbf{1 d} \cdot{ }^{55}$ Once glycerol is converted to hydroxyacetone, the latter is transformed to 2-hydroxy-1-propanal via a keto-enol tautomerism. The aldehyde undergoes a condensation with aniline to form a $\alpha$-hydroxyimine intermediate. Then, the 
loss of a second molecule of water generates a secondary carbocation able to trigger a ring closure which provides the final indole derivative. ${ }^{54}$

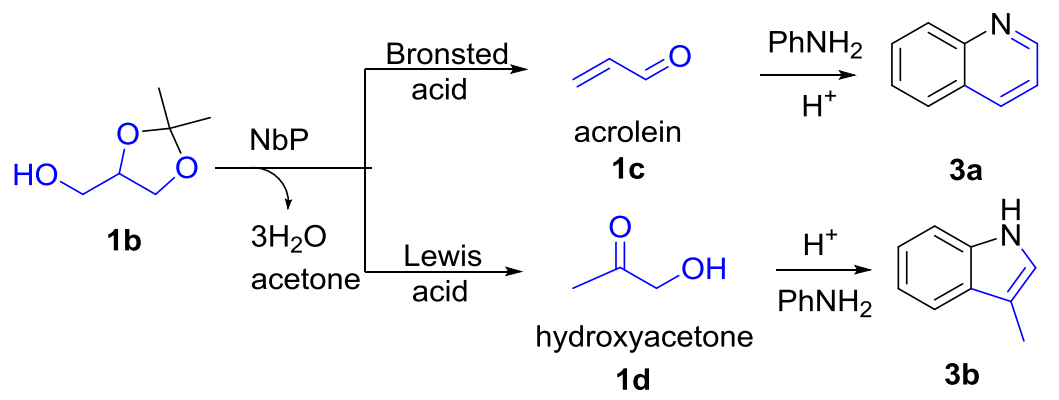

Scheme 3. Main by-product observed from the continuous flow reaction of solketal $\mathbf{1 b}$ and aniline $\mathbf{2 a}$ over Niobium phosphate (NbP). (a) Synthesis of quinoline 3a through acrolein 1c over Brønsted acid sites and (b) synthesis of 3-methylindole $\mathbf{3} \mathbf{b}$ through hydroxyacetone $\mathbf{1 d}$ intermediate over Lewis acid sites.

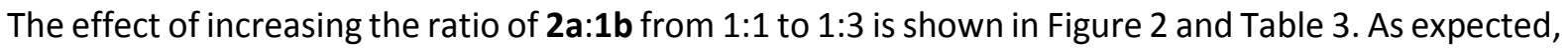
increasing the ratio has a positive effect on conversion of aniline. However, after a few hours, there is very little difference in the selectivity for quinoline 3a between the different experiments. By contrast, the lifetime of the catalyst appears to be reduced at the higher ratios, presumably because of coking process via the polymerisation of acrolein. The higher concentration of water, coproduced with acrolein may also have an effect. A lower amount of solketal has been fed (ratio 2:1) to minimize acrolein degradation with a result similar to the stoichiometric ratio for both conversion and selectivity over 15 hours.
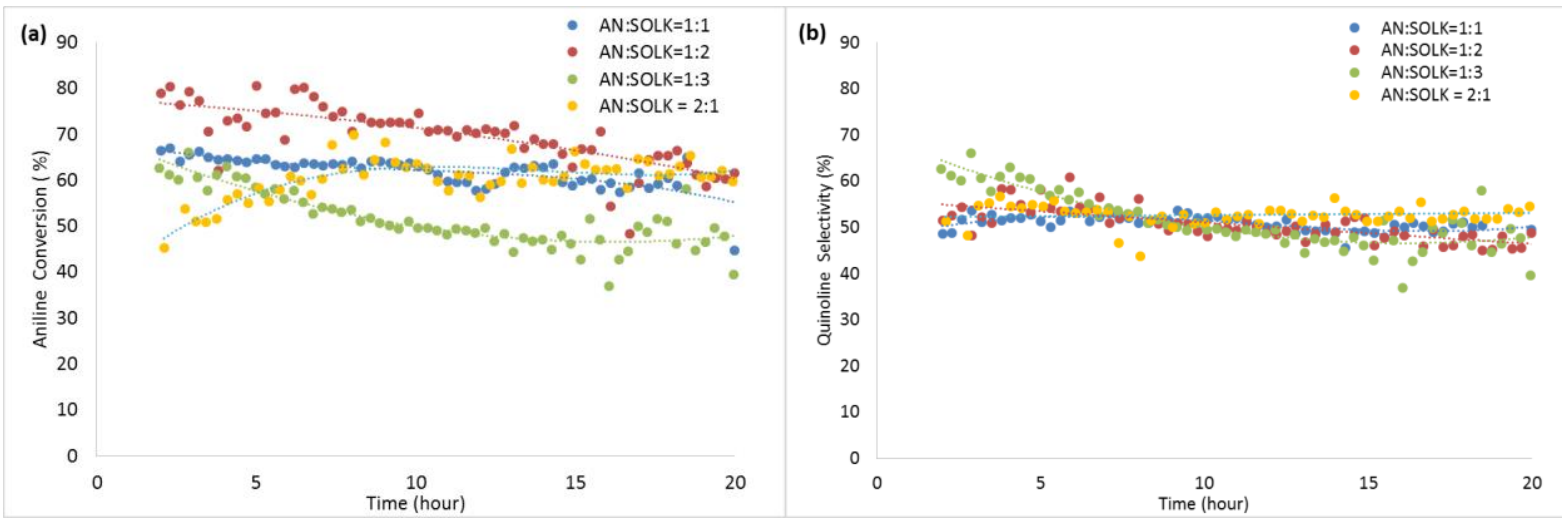

Figure 2. Plots illustrating that the ratio reagent has relatively little effect on the (a) conversion of aniline and (b) quinoline selectivity over NbP. The different experiments were performed under the following conditions: $250{ }^{\circ} \mathrm{C}$, NbP catalyst, $0.2 \mathrm{~mL} / \mathrm{min}$ of total flowrate and $10 \mathrm{MPa}$ for $1: 1$ (blue), 1:2 (red), 1:3 (green) and 2:1 (yellow) ratios of 2a:1b. 
Table 3. Influence of the reagents ratio effect on the conversion of aniline, the selectivity and productivity of quinoline $3 \mathrm{a}$ over $\mathrm{NbP}$.

\begin{tabular}{lcccc}
\hline 2a:1b ratio & $\mathbf{1 : 1}$ & $\mathbf{1 : 2}$ & $\mathbf{1 : 3}$ & $\mathbf{2 : 1}$ \\
\hline Aniline conversion $^{\mathrm{a}}$ & $63 \%$ & $73 \%$ & $72 \%$ & $61 \%$ \\
Quinoline selectivity $^{\mathrm{a}}$ & $51 \%$ & $52 \%$ & $53 \%$ & 52 \\
Quinoline productivity & $0.068 \mathrm{~g} / \mathrm{h}$ & $0.08 \mathrm{~g} / \mathrm{h}$ & $0.08 \mathrm{~g} / \mathrm{h}$ & $0.065 \mathrm{~g} / \mathrm{h}$ \\
\hline
\end{tabular}

a The conversion, selectivity and productivity were averaged values of the reaction from $2^{\text {nd }}$ to $15^{\text {th }}$ hour and calculated based on GC analysis. Reaction conditions were $2 \mathrm{a}: 1 \mathbf{b}$ ratio of $1: 1$ and $0.2 \mathrm{ml} / \mathrm{min}$ total flowrate, $250^{\circ} \mathrm{C}$ at $10 \mathrm{MPa}$.

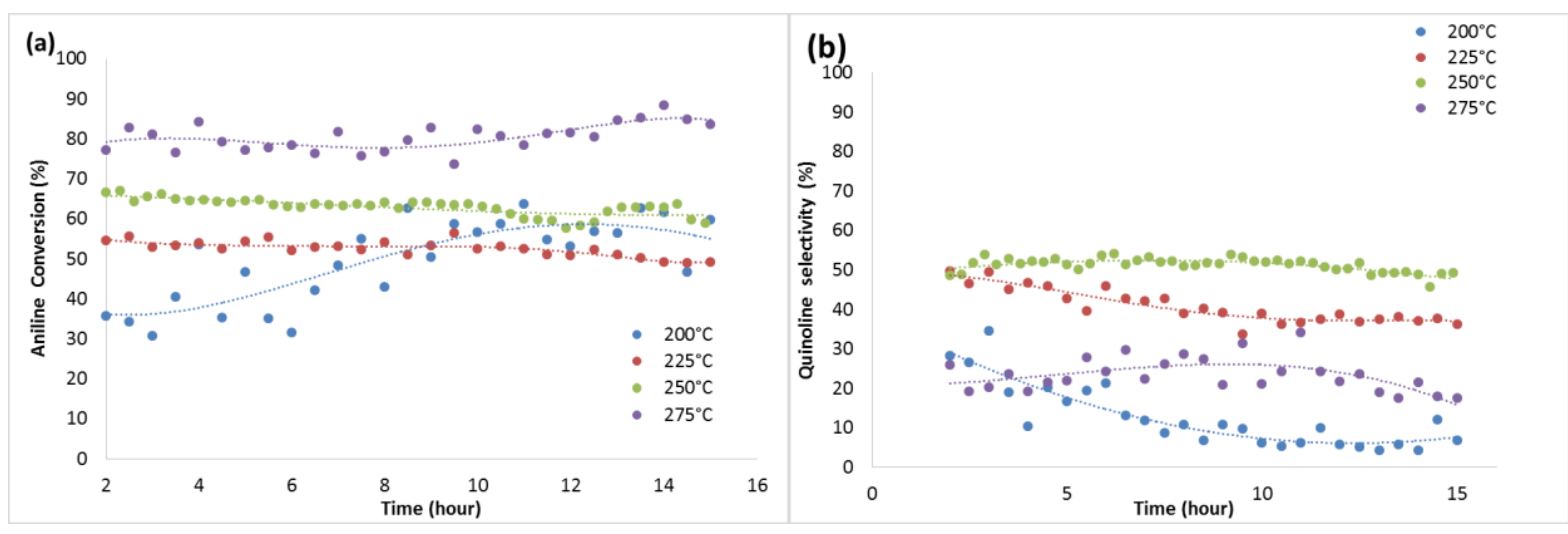

Figure 3. Effect of the temperature on (a) aniline conversion and (b) quinoline selectivity of four sets of experiments were carried out isothermally at 225,250 and $275^{\circ} \mathrm{C}$ at $10 \mathrm{MPa}$ with a constant reagent 2a:1b ratio of 1:1. Two $0.275 \mathrm{M}$ solutions of solketal and aniline were set to a total flowrate of 0.2 $\mathrm{mL} / \mathrm{min}$. The dotted lines are purely to aid visualization.

The effect of temperature was more striking. As shown in Figure 3, the conversion of aniline increases with temperature from $53 \%$ at $225^{\circ} \mathrm{C}$ up to $78 \%$ at $275^{\circ} \mathrm{C}$ and, although not illustrated, it increases to $85 \%$, at $300{ }^{\circ} \mathrm{C}$ (Table 4). Selectivity however drops to $20-30 \%$ at $275{ }^{\circ} \mathrm{C}$ and only $10 \%$ at $300{ }^{\circ} \mathrm{C}$. This observation is possibly due to the different effects of temperature on the relative rates of generation of acrolein from solketal and its subsequent polymerization. 
Table 4. Aniline conversion, quinoline selectivity and productivity measured as function of temperature.

\begin{tabular}{cccccc}
\hline Temperature & $\mathbf{2 0 0} \mathbf{C}$ & $\mathbf{2 2 5}^{\circ} \mathbf{C}$ & $\mathbf{2 5 0}^{\circ} \mathbf{C}$ & $\mathbf{2 7 5}^{\circ} \mathbf{C}$ & $\mathbf{3 0 0}^{\circ} \mathbf{C}$ \\
\hline Aniline conversion $^{\mathrm{a}}$ & $45 \%$ & $53 \%$ & $64 \%$ & $78 \%$ & $85 \%$ \\
Quinoline selectivity $^{\mathrm{a}}$ & $16 \%$ & $42 \%$ & $52 \%$ & $24 \%$ & $10 \%$ \\
Quinoline productivity & $0.015 \mathrm{~g} / \mathrm{h}$ & $0.49 \mathrm{~g} / \mathrm{h}$ & $0.68 \mathrm{~g} / \mathrm{h}$ & $0.04 \mathrm{~g} / \mathrm{h}$ & $0.05 \mathrm{~g} / \mathrm{h}$
\end{tabular}

${ }^{a}$ The conversion, selectivity and productivity were averaged values of the reaction from $2^{\text {nd }}$ to $15^{\text {th }}$ hour and calculated based on GC analysis. Reaction conditions: $2 \mathbf{a}: \mathbf{1 b}$ ratio of $1: 1$, total flowrate of 0.2 $\mathrm{mL} / \mathrm{min}$ at $10 \mathrm{MPa}$.

A modest scale-up of the reaction was attempted using three reactors filled with $\mathrm{NbP}$ in series with a fourth reactor placed upstream and filled with sand to act as pre-mixer $\left(\mathbf{R}_{\mathbf{b}}-20 \mathrm{~cm}\right.$ length, $\varnothing=1 / 4$ " each and $\sim 4.5 \mathrm{~mL}$ ) as described in experimental section and in previous work. ${ }^{59}$ The flow rate was initially set at the same value $(0.1 \mathrm{~mL} / \mathrm{min})$ of each reagent. The triple reactor ran for 60 hours before any fall off in conversion was detected. By comparison, the single reactor showed significant fall off in less than 20 hours (one reactor $\mathbf{R}_{\mathbf{a}}, 0.1 \mathrm{~mL} / \mathrm{min}$ ). When the flow rate through the triple reactor was increased by a factor of three, its temporal behaviour was similar to that of the single reactor; indeed the fall off in both conversion and selectivity was more dramatic (Figure 4). This suggests that there may be a relationship between the amount of substrate passing through the reactor and the active lifetime of the NbP (Table 5).
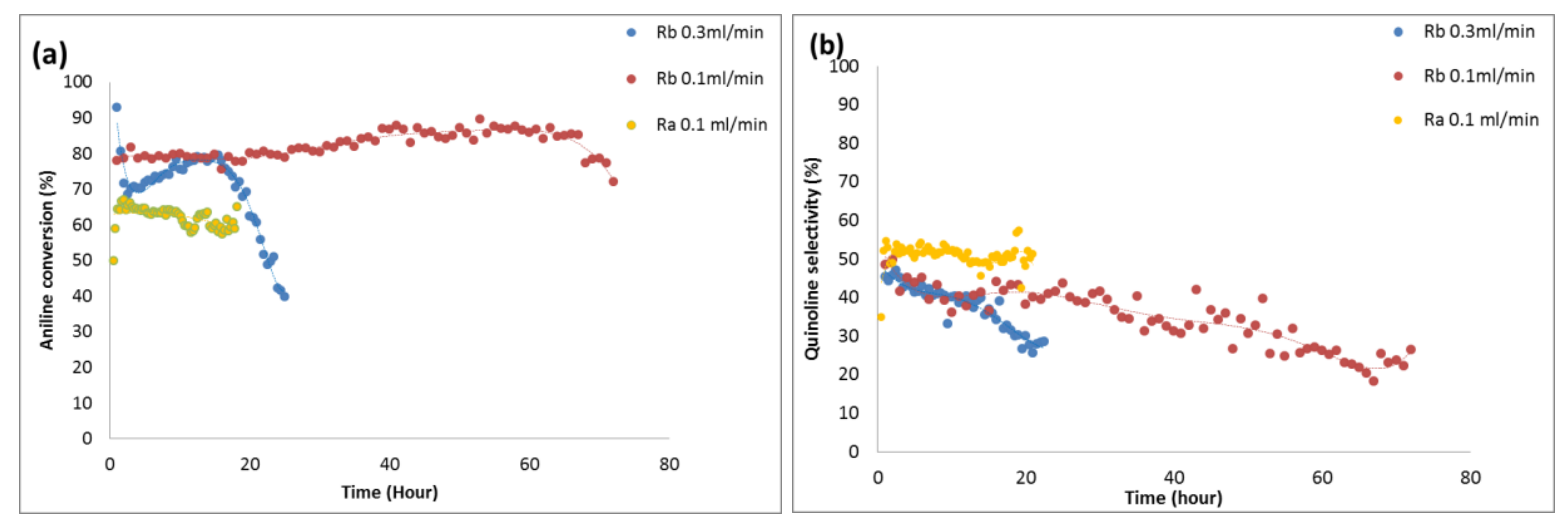

Figure 4. Scaled-up Continuous flow quinoline synthesis in series. (a) Aniline conversion and (b) selectivity to quinoline study under the same conditions of those in Figure $3\left(250{ }^{\circ} \mathrm{C}, 10 \mathrm{MPa}\right)$. 
Equimolar solutions of both reactants $\mathbf{2 a}$ and $\mathbf{1 b}$ were fed at flow rates of 0.1 and $0.3 \mathrm{~mL} / \mathrm{min}$. The yellow profile is the same as in Figure 3 and it is reported here for comparison.

Table 5. Scale-up Continuous Flow Skraup reaction productivity comparison for the one reactor $\mathbf{R}_{\mathbf{a}}$ versus the triple reactor $\mathbf{R}_{\mathbf{b}}$ setup at various flow rates.

Total

$1.2 \mathrm{~g} \mathrm{NbP}$ Cat.

$1.2 \mathrm{~g} * 3 \mathrm{NbP}$ Cat.

Flowrate

$\begin{array}{lcc}\text { Aniline } & \text { Quinoline } & \text { Quinoline } \\ \text { Conv. }^{a} & \text { Sel. }{ }^{a} & \text { productivity }\end{array}$

TON

Aniline

Quinoline

Quinoline

TON

Conv. Sel. productivity

$\left(T O F, s^{-1}\right)^{b}$

Conv. ${ }^{\text {a }}$ Sel. ${ }^{\text {a }}$ productivity

$\left(T O F, s^{-1}\right)^{b}$

\begin{tabular}{|c|c|c|c|c|c|c|c|c|}
\hline $0.2 \mathrm{ml} / \mathrm{min}$ & $63 \%$ & $51 \%$ & $0.068 \mathrm{~g} / \mathrm{h}$ & $\begin{array}{c}4.33 \\
\left(0.57 \times 10^{-3}\right)\end{array}$ & $79 \%$ & $41 \%$ & $0.07 \mathrm{~g} / \mathrm{h}$ & $\begin{array}{c}1.45 \\
\left(0.24 \times 10^{-3}\right)\end{array}$ \\
\hline $0.6 \mathrm{ml} / \mathrm{min}$ & & & & & $74 \%$ & $41 \%$ & $0.19 \mathrm{~g} / \mathrm{h}$ & 4.09 \\
\hline
\end{tabular}

$\left(0.67 \times 10^{-3}\right)$

${ }^{a}$ The conversion, selectivity and productivity were averaged values of the reaction from over 15 hour and calculated based on GC analysis. The different experiments were performed under the following conditions: $\mathbf{2 a}: \mathbf{1 b}$ ratio of $1: 1$ at $250^{\circ} \mathrm{C}$ and $10 \mathrm{MPa}$. ${ }^{\mathrm{b}}$ Turnover frequency (TOF) has been calculated relative to the number of acid site as followed: TOF= number quinoline formed/number of $\mathrm{NbP}$ acid site. The number of acid sites is based on pyridine desorption. ${ }^{61}$

Scheme 4 sketches a possible mechanism for the Skraup reaction catalysed by NbP. Even under our best conditions, the conversion of aniline and the selectivity towards quinoline did not exceed $80 \%$ and $60 \%$, respectively. The moderate yields can be understood by considering the overall reaction which occurs through three consecutive catalytic steps. Available data indicate that the dehydration of glycerol over $\mathrm{NbP}$ or mesoporous siliconiobium phosphate as (doped) catalysts proceeds with conversion and selectivity from 68 to $100 \%$ and from 70 to $75 \%$, respectively. ${ }^{45,46,34}$ It is therefore likely that, once the dehydration of glycerol is coupled to the other two catalytic steps (i.e. the ketal deprotection and the condensation of acrolein with aniline), the overall yield will be low. 


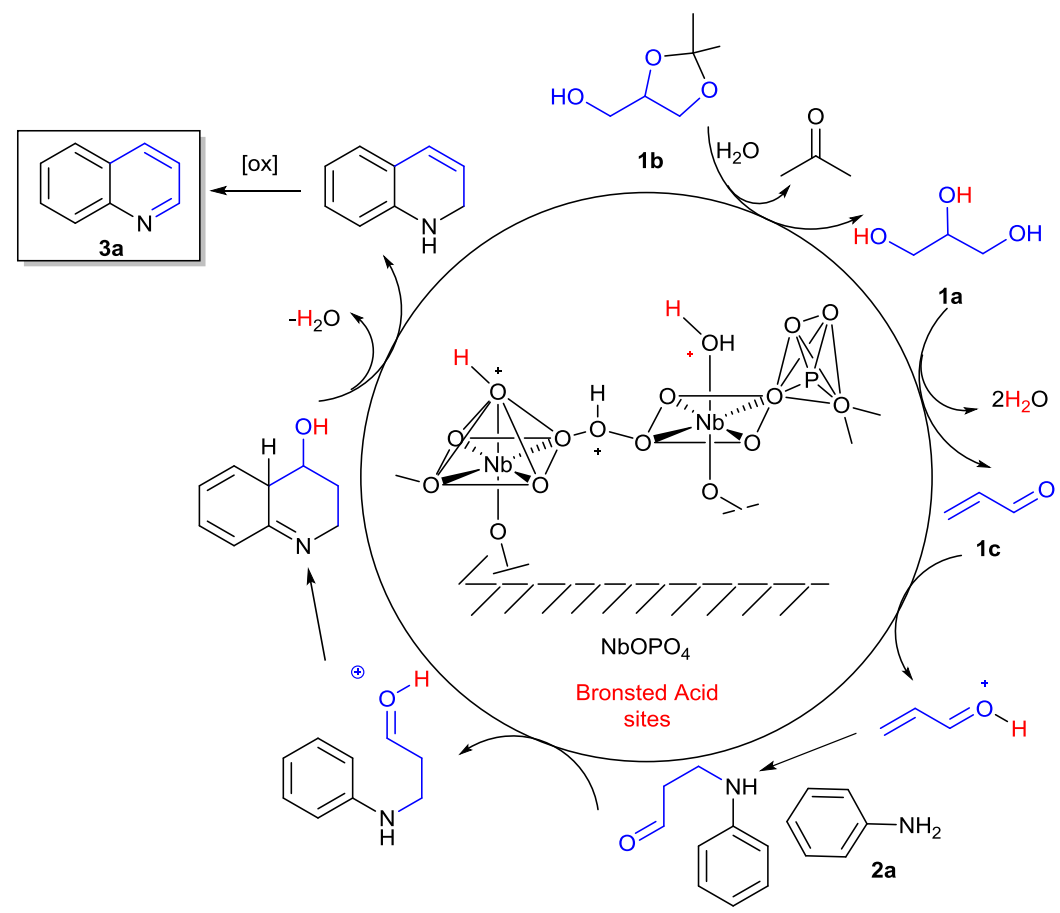

Scheme 4. One possible acid-catalyzed mechanism for the formation of quinoline, based on papers cites in our introduction, starting from Solketal $\mathbf{1} \mathbf{b}$ and aniline $\mathbf{2 a}$ over niobium phosphate (NbP). ${ }^{60}$ None of the postulated intermediates nor any other were detected presumably because whatever intermediates formed are unstable under our conditions.

Two of the steps in Scheme 4 might be causing the decline in catalytic steps. The first is coking caused by polymerization of the free acrolein. The other is the final oxidation step leading to the formation of 3a. The literature suggests that the acidity ${ }^{61}$ strength of the most selective catalysts for the dehydration of glycerol to acrolein lies between $8.2 \leq \mathrm{H}_{0} \leq-3.0 .{ }^{23}$ Systems having very strong acid activities ( $\left.H_{0} \leq-8.2\right)$, such as $\mathrm{NbP}$, may offer low acrolein selectivity (40-50\%) due to the onset coke deposition during the reaction. The dehydration process usually requires high temperatures (250 $300{ }^{\circ} \mathrm{C}$ ) and acrolein can easily undergoes undesired polymerization and coke formation. ${ }^{62}$ Various approaches have been proposed to limit the deactivation of dehydration catalysts. ${ }^{24}$ These include the suppression of the rate of coking by adding $\mathrm{O}_{2}$ or $\mathrm{H}_{2}$ to the feed flow ${ }^{63,64,65}$ and modifying the catalysts with promoters to change the acid properties of the catalysts. We have found that the deactivation of $\mathrm{NbP}$ is related to the amount of solketal (and thus, of glycerol) used in the reaction. The more solketal is delivered to the reactor, the more acrolein is formed and consequently, the larger the coke deposition over the catalyst active phase. TGA traces shown in ESI for the used catalyst are consistent with the presence of organic coking.

There seems to be no obvious reason why polymerization should give rise to the near stoichiometric behavior which we observed. On the other hand, the oxidation step must give rise to a corresponding 
reduction of the surface. Such reduction would be expected to be close to the stoichiometric. Whichever of the explanations is correct, the route to regenerating the spent $\mathrm{NbP}$ may well be heating under a stream of air. We found that heating up to $300{ }^{\circ} \mathrm{C}$ for 20 hours was unsuccessful and, unfortunately, our reactors could not be heated to higher temperature without compromising their pressure rating. ${ }^{32}$

Control experiments were carried out to establish whether the acetone liberated from the solketal might be reacting with aniline as this compound 2,2,4- trimethyl-1,2-dihydroquinoline $\mathbf{4 b}$ has been reported ${ }^{66}$ from the reaction of aniline with acetone over zeolite catalysts but also halide acid clusters in vapour phase above $200^{\circ} \mathrm{C} .{ }^{67}$ Therefore, a $0.275 \mathrm{M}$ solution feed of acetone in toluene was used instead of the solketal solution under the same reaction conditions as Figure 3 at $250^{\circ} \mathrm{C}$. Less than 8 $\%$ yield of two products 2,4-dimethylquinoline $\mathbf{4 a}$ and 2,2,4- trimethyl-1,2-dihydroquinoline $\mathbf{4 b}$ was obtained (Scheme 5). The products were isolated and characterized by MS and NMR analysis (See supporting information). However, these products were not detected in any of our reactions carried out with solketal, demonstrating clearly that the acetone is unlikely to take part in any side reactions in our system under these conditions.

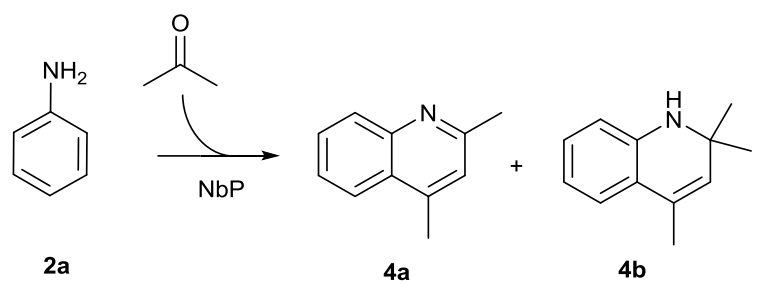

Scheme 5. Condensation of acetone with aniline in the absence of solketal over NbP to give compounds $4 \mathrm{a}$ and $4 \mathrm{~b}$. The same reaction products have been reported over zeolite catalyst. ${ }^{67}$

In order to demonstrate that $\mathrm{NbP}$ can be extended to catalyse the Skraup reaction more widely, two anilines, 4-methoxyaniline and 4,4'-methylenedianiline ( $\mathbf{2 b}$ and $\mathbf{2 c}$ in Scheme 6) were used to react with solketal. The expected heterocyclic quinoline product was formed as the major component in both the cases. 


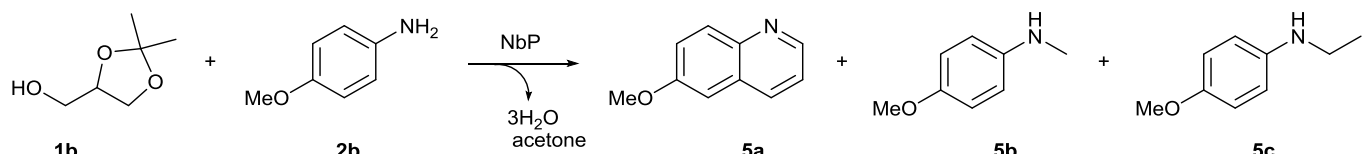

1b

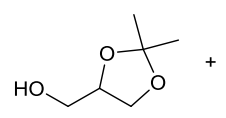

$1 \mathrm{~b}$

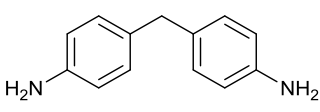

2c

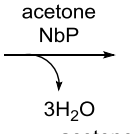

acetone

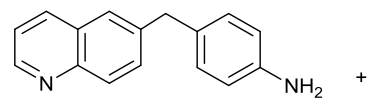

$6 a$

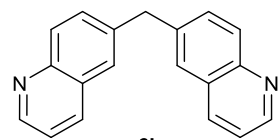

6b

Scheme 6. Products observed from the continuous flow reaction of 4-methoxyaniline $\mathbf{2} \mathbf{b}$ and $4,4^{\prime}$ methylenedianiline $\mathbf{2 c}$ with solketal over niobium phosphate (NbP).

We began with best reaction conditions found for aniline itself i.e. $1: 1$ ratio, $250^{\circ} \mathrm{C}$ and $10 \mathrm{MPa}$. With 4-methoxyaniline, the 6-methoxyquinoline 5 a was obtained with a GC-yield of $30 \%$. The two main byproducts observed were 4-Methoxy- $\mathrm{N}$-methylaniline $\mathbf{5 b}$ and $\mathrm{N}$-Ethyl-4-methoxyaniline $\mathbf{5 c}$ (Total amount $<10 \%$ ). All these compounds were isolated and characterized by NMR and MS (see the ESI). The process was not further optimised.

For the toxic 4,4'-methylenedianiline $2 \mathrm{c}(\mathrm{MDA})$, a higher temperature of $300{ }^{\circ} \mathrm{C}$ was necessary to increase the aniline conversion with a 1:1 mixture of $\mathbf{2 c : 1 b}$. Both the dissymmetric $\mathbf{6 a}$ and symmetric $\mathbf{6 b}$ products were observed with a GC-yield of 20 and $12 \%$ respectively. A crystal of compound 6 a was grown and the structure determined by crystallographic analysis for the first time. The compounds were isolated and characterized by MS and NMR analysis (see experimental section). It is interesting that the major product is the desymmetrized compound $\mathbf{6 a}$.

\section{Conclusions}

The experiments described here are useful proof of concept. Solketal can be used as a feedstock for the continuous Skraup reaction promoted by a niobium phosphate solid acid catalyst. No liquid acids or added oxidants are needed. It therefore adds to the range of transformations that can be carried out using glycerol, a by-product product of the energy industry. Although the reaction contravenes the sixth Principle of Green Chemistry in that it requires high temperature and pressure, it should be noted that: i) the high pressure may not be a substantial hindrance since the reactants are liquids and therefore relatively incompressible requiring little energy to be pressurized; and ii) technologies for the integrated heat recovery in modern biorefineries allow a cheap access to temperatures up to $300{ }^{\circ} \mathrm{C}$. 
The major problem still to be addressed is how best to regenerate the niobium catalyst. Heating the catalyst to $300^{\circ} \mathrm{C}$ in air had little effect. Our TGA experiment suggests that at much higher temperature calcination may be effective. Even at the current stage of development, however, the reaction could provide a convenient route to less common quinolines such as the desymmetrized $6 \mathbf{a}$. From a sustainability point of view the key points are that a continuous Skraup reaction is possible and can be catalysed by niobium phosphate a relatively inexpensive and abundant metal in a continuous flow process.

As explained above, we have used solketal because the limitations of our small-scale equipment prevent the efficient pumping of glycerol. Those experiments which we did perform with glycerol gave poor selectivity. We attributed the better selectivity which we observed with solketal as being due to the better control of the equipment which we could achieve with this substrate. However, there remains the intriguing possibility that solketal may give inherently better selectivity than glycerol itself under these reaction conditions. If this were the case, solketal would be the preferred starting material for this process of valorisation of the glycerol by-product. Unfortunately we have insufficient data to test this possibility. Nevertheless, the point should be explored before dismissing the use of solketal as unnecessary derivitisation, in contravention of the eighth Principle of Green Chemistry (i.e. "unnecessary derivatization [blocking group, protection/deprotection, temporary modification of physical/chemical processes] should be avoided whenever possible"). For the moment, it is clear that solketal is potentially an alternative to glycerol for smaller scale reactions, even if glycerol may eventually turn out to be preferable from a Green Chemistry point of view for larger scale processes.

\section{Experimental}

All the continuous flow experiments were carried out using a simple system consisting of a stainless steel tubular reactor (1/4 in. OD) or a 4 tubular reactors in series for the scale-up as detailed in ESI. The reactors were filled with the Niobium phosphate catalyst without any treatment $(1.2 \mathrm{~g})$. A tubular pre-mixer was filled with sand and attached before the reactor. The regents were delivered using HPLC pumps and were flowed through the reactor in a downward direction. A back pressure regulator was used to maintain and adjust the system pressure. The reaction requires specific sensors linked to trip box to ensure safety requirements for high temperature and pressure conditions. An in-line GC/FID, placed between the reactor and the BPR, was used to automatically sample and analyse the reaction controlled by MathLab software. Niobium Phosphate was supplied as powder form by CBMM and 1.2 
$\mathrm{g}$ (unless specified otherwise) was packed into the reactor without any treatment. The system was set to the studied parameter approximatively 10 to $25 \mathrm{~h}$. The conversion and selectivity were determined at regular intervals, by analyzing samples taken online GC from the reaction medium for calculation of the conversion and selectivity.

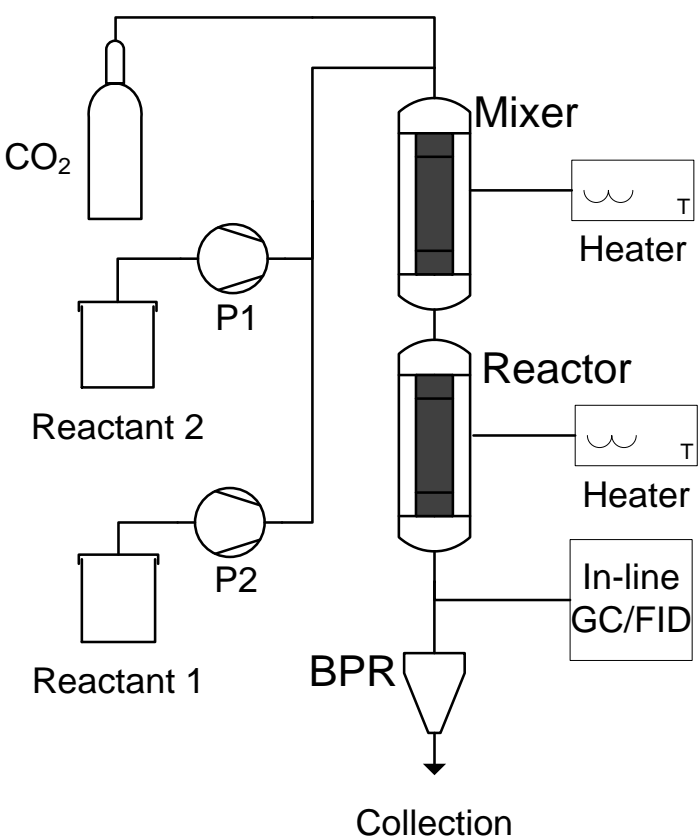

Figure 5. Schematic apparatus for the continuous flow niobium phosphate catalysed quinoline synthesis

\section{Acknowledgements}

Financial support for JJ's PhD by the Companhia Brasileira de Metalurgia e Mineração (CBMM) is gratefully acknowledged as well as the supply of Niobium catalysts. We thank Richard Wilson, Peter Field and Mark Guyler for technical support. We also thank William Lewis for the crystallographic analysis of 6a and Shazad Asalam for NMR assistance.

\section{Notes and references}

\footnotetext{
${ }^{1}$ C.-H. Zhou, J.N. Beltramini, Y.-X. Fan and G. Q. Lu, Chem. Soc. Rev., 2008, 37, 527-549.

${ }^{2}$ C. B. Field, M. J. Behrenfeld, J. T. Randerson, P. Falkowski Science 1998, 281, 237-239.

${ }^{3}$ H. F. Sneddon Green Chem. 2016, 18, 5082-5085.

${ }^{4}$ C. A. G. Quispe, C. J.R. Coronado, J.A. Carvalho Renew. Sus. En. Rev. 2013, 27, 475-493.

${ }^{5}$ W. Borzani Brazilian J. Microbiol. 2006, 37, 87-9.

${ }^{6}$ A. Behr, J. Eilting, K. Irawadi, J. Leschinski, F. Lindner, Green Chem., 2008, 10, 13-30.

${ }^{7}$ M. Pagliaro, R. Ciriminna, H. Kimura, M. Rossi, C. D. Pina, Angew. Chem., Int. Ed., 2007, 46, 4434.
} 
${ }^{8}$ F. Jérôme, Y. Pouilloux, J. Barrault, ChemSusChem, 2008, 1, 586.

${ }^{9}$ A. Behr, J. Eilting, E. Pérez, A. Garrido, J. Peinado Energy \& Fuels, 2008, 22, 4274-4280.

${ }^{10}$ C. Len, R. Luque Sustain. Chem. Process., 2014, 2, 1.

${ }^{11}$ B. Katryniok, S. Paul, F. Dumeignil ACS Catal., 2013, 3, 1819-1834.

${ }^{12}$ M. B. Yadav, S. Kulkarni, R. A. Joshi, A. A. Kulkarni Org. Proc. Res. Dev., 2016, 10, 1621

${ }^{13}$ Z. H. Skraup, Monatsh. Chem., 1880, 1, 316-318.

${ }^{14}$ Z. Wang, Skraup Reaction in Comprehensive Organic Name Reactions and Reagents, John Wiley \& Sons, Inc., 2010.

${ }^{15}$ G. A. Ramann, B.J. Cowen Tetrahedron Lett., 2015, 56, 6436-6439.

${ }^{16}$ X.-G. Li, X. Cheng and Q.-L. Zhou, Synth. Commun., 2002, 32, 2477-2481.

${ }^{17}$ X. Zhang and X. Xu, Chem. As. J., 2014, 9, 3089-3093.

18 J. Horn, S. P. Marsden, A. Nelson, G. G. Weingarten Org. Lett., 2008, 10, 4117-4120.

${ }^{19}$ Y. Hamada, I. Takeuchi Chem. Pharm. Bull., 1971, 19, 1857.

${ }^{20}$ M. C. Kozlowski et al. Org. Lett. 2000, 2, 875.

${ }^{21}$ G. A. Ramann and B. J. Cowen Molecules 2016, 21, 986.

${ }^{22}$ C.-J. Jia, Y. Liu, W. Schmidt, A.-H. Lu, F. Schuth J. Catal., 2010, 269, 71-79.

${ }^{23}$ K. Pathak, K. M. Reddy, N. N. Bakhshi, A. K. Dalai Appl. Catal., A, 2010, 372, 224-238.

${ }^{24}$ B. Katryniok, S. Paul, V. Bellière-Baca, P. Rey, F. Dumeignil Green Chem., 2010, 12, 2079.

${ }^{25}$ B. Katryniok, S. Paul, M. Capron, C. Lancelot, P. Rey, F. Dumeignil Green Chem., 2010, 12, 1922.

${ }^{26}$ E. Tsukuda, S. Sato, R. Takahashi, T. Sodesawa Catal. Commun., 2007, 8, 1349-1353.

${ }^{27}$ P. Lauriol-Garbay, J. M. M. Millet, S. Loridant, V. Bellière-Baca, P. Rey J. Catal., 2011, 280, 68-76.

${ }^{28}$ L.-Z. Tao, S.-H. Chai, Y. Zuo, W.-T. Zheng, Y. Liang, B.-Q. Xu Catal. Today, 2010, 158, 310-316.

${ }^{29}$ N. R. Shiju, D. R. Brown, K. Wilson, G. Rothenberg Top. Catal., 2010, 53, 1217-1223.

${ }^{30}$ Z. Amara, E. S. Streng, R. A. Skilton, J. Jin, M. W. George, M. Poliakoff Eur. J. Org. Chem. 2015, 2015, 61416145.

${ }^{31}$ M. J. C. Molina, M.L. Granados, A. Gervasini, P. Carniti Catal. Today, 2015, 254, 90-98.

${ }^{32}$ Y. Zhang, J. Wang, J. Ren, X. Liu, X. Li, Y. Xia, G. Lu, Y. Wang Catal. Sci. \& Technol., 2012, 2, 2485.

${ }^{33}$ J. Xi, Y. Zhang, D. Ding, Q. Xia, J. Wang, X. Liu, G. Lu, Y. Wang Appl. Catal. A, 2014, 469, 108-115.

${ }^{34}$ L. C. A. Oliveira, M. F. Portilho, A. C. Silva, H. A. Tarocoa, P. P. Souza App. Catal. B, 2012, 117-118, 29-35.

${ }^{35}$ T. lizuka, K. Ogasawara, K. Tanabe Bull. Chem. Soc. Jpn., 1983, 56, 2927-2931.

${ }^{36}$ M. Ziolek, Catal. Today 2003, 78, 47-64.

${ }^{37}$ C Guo, Z. Qian Catal. Today 1993, 16, 379.

38 T. Ushikubo, T. lizuka, H. Hattori, K. Tanabe, Catal.Today 1993, 16, 291.

${ }^{39}$ A. Florentino, P. Cartraud, P. Magnoux, M. Guisnet Appl. Catal., A, 1992, 89, 143-153.

${ }^{40}$ M. Moraes, W. d. S. F. Pinto, W. A. Gonzalez, L. M. P. M Carmo, N. M. R. Pastura, E. R. Lachter Appl. Catal., A, 1996, 138, L7-L12.

${ }^{41}$ I. Rossetti, M. Compagnoni Chem. Eng. J. 2016, 296, 56-70.

${ }^{42}$ C. G. Frost, L. Mutton Green Chem., 2010, 12, 1687

${ }^{43}$ V. V. Ordomsky, V.L. Sushkevich, J.C. Schouten, J. Van Der Schaaf, T.A. Nijhuis, J. Catal., 2013, 300, 37-46.

${ }^{44}$ S. Okazaki and A. Kurosaki, Catal. Today, 1990, 8, 113-12; Y. Zhang, J.J. Wang, X.C. Li, X. H. Liu, Y.J. Xia, B.C. Hu, G. Z. Lu, Y. Q. Wang, Fuel, 2015, 139, 301-307.

${ }^{45}$ Y. Choi, D. S. Park, H. J. Yun, J. Baek, D. Yun, J. Yi ChemSusChem, 2012, 5, 2460-2468.

${ }^{46}$ Y. Y. Lee, K. A. Lee, N. C. Park, Y. C. Kim Catal. Today, 2014, 232,114-118.

${ }^{47}$ S. Okazaki, N. Wada, Catal. Today 1993, 16, 349-359.

${ }^{48}$ K. Nakajima, Y. Baba, R. Noma, M. Kitano , J. N. Kondo, S. Hayashi, M. Hara, J. Am. Chem. Soc., 2011, 133, 42244227.

49 J. C. Smith, R. E. Drexel, Ind. \& Eng. Chem., 1945, 37, 601-602.

${ }^{50}$ D. Royon, S. Locatelli, E. E. Gonzo J. Supercritical Fluids 2011, 58, 88-89.

${ }^{51}$ S. Bagheri, N. Muhd Julkapli , W. A. Yehye Renew. Sus.En. Rev. 2015, 41, 113-127.

${ }_{52}$ M. Selva, S. Guidi, M. Noè Green Chem. 2015, 17, 1008-1023.

${ }^{53}$ S. Guidi, R. Calmanti, M. Noè, A. Perosa, M. Selva, ACS Sustainable Chem. Eng., 2016, 4, 6144-6151.

${ }^{54}$ Y. Cui, X. Zhou, Q. Sun, et al.,J. Mol. Catal. A: Chem., 2013, 378, 238-245.

${ }^{55}$ M. Velasquez, A. Santamaria, C. Batiot-Dupeyrat, Appl. Catal. B, 2014, 160-161, 606-613.

${ }^{56}$ S. Sato, D. Sakai, F. Sato, Y. Yamada Chem. Lett,. 2012, 41, 965-966.

${ }^{57}$ C.-W. Chiu, M. A. Dasari, G. J. Suppes, W. R. Sutterlin AlChE J., 2006, 52, 3543-3548.

${ }^{58}$ A. Alhanash, E. F. Khozevnikova, I. V. Khozevnikov Appl. Catal., 2010, 378, 11. 
${ }^{59}$ D. S. Lee, Z. Amara, M. Poliakoff, T. Harman, G. Reid, B. Rhodes, S. Brough, T. Mclnally, S. Woodward Org. Proc. Res. Dev., 2015, 19, 831-840.

60 N. R. Chernonukov, N. P. Egonov, I. R. Mochalova Russ. J. Inorg. Chem., 1978, 23, 1627.

${ }^{61}$ P. Carniti, A. Gervasini, S. Biella, A. Auroux, Chem. Mater., 2005, 17, 6128-6136

${ }^{62}$ A. Corma, G. Huber, L. Sauvanaud, P. O'Connor J. Catal., 2008, 257, 163-171.

${ }^{63}$ A. Ulgen and W. Hoelderich, Catal. Lett., 2009, 131, 122-128.

${ }^{64}$ F. Wang, J.-L. Dubois, W. Ueda, J. Catal., 2009, 268, 260-267.

${ }^{65}$ F. Wang, J. Xu, J. L. Dubois, W. Ueda ChemSusChem, 2010, 3, 1383-1389.

${ }^{66}$ A. Hegedüs, Z. Hell, T. Vargadi, A.Potor, I. Gresits Catal. Lett. 2007, 117, 99-101.

${ }^{67}$ S. Kamiguchi, I. Takahashi, H. Kurokawa, H. Miura, T. Chihara Appl. Catal. A 2006, 309, 70-75. 